\section{(A) OPEN ACCESS}

\title{
International variation in absence from work attributed to musculoskeletal illness: findings from the CUPID study
}

\author{
David Coggon, ${ }^{1}$ Georgia Ntani, ${ }^{1}$ Sergio Vargas-Prada, ${ }^{2}$ José Miguel Martinez, ${ }^{2,3}$ \\ Consol Serra, ${ }^{2,3,4}$ Fernando $G$ Benavides, ${ }^{2,3}$ Keith T Palmer, ${ }^{1}$ and other members of \\ the CUPID Collaboration
}

\begin{abstract}
${ }^{1}$ Medical Research Council Lifecourse Epidemiology Unit, University of Southampton, Southampton, UK ${ }^{2}$ Center for Research in Occupational Health (CISAL) Universitat Pompeu Fabra, Barcelona, Spain ${ }^{3}$ CIBER of Epidemiology and Public Health, Barcelona, Spain ${ }^{4}$ Occupational Health Service, Parc de Salut MAR, Barcelona, Spain
\end{abstract}

\section{Correspondence to} Professor David Coggon, Medical Research Council Lifecourse Epidemiology Unit, Southampton General Hospital Southampton SO16 6YD, UK; dnc@mrc.soton.ac.uk

Received 14 December 2012 Revised 9 April 2013 Accepted 15 April 2013 Published Online First 21 May 2013

\footnotetext{
To cite: Coggon $D$, Ntani G, Vargas-Prada S, et al. Occup Environ Med 2013;70:575-584.
}

\begin{abstract}
Objectives To quantify the variation in rates of absence due to musculoskeletal pain across 47 occupational groups (mostly nurses and office workers) from 18 countries, and to explore personal and grouplevel risk factors that might explain observed differences. Methods A standardised questionnaire was used to obtain information about musculoskeletal pain, sickness absence and possible risk factors in a cross-sectional survey of 12416 workers (92-1017 per occupational group). Additionally, group-level data on socioeconomic variables, such as sick pay and unemployment rates, were assembled by members of the study team in each country. Associations of sickness absence with risk factors were examined by Poisson regression.

Results Overall, there were more than 30-fold differences between occupational groups in the 12month prevalence of prolonged musculoskeletal sickness absence, and even among office workers carrying out similar occupational tasks, the variation was more than tenfold. Personal risk factors included older age, lower educational level, tendency to somatise, physical loading at work and prolonged absence for non-musculoskeletal illness. However, these explained little of the variation between occupational groups. After adjustment for individual characteristics, prolonged musculoskeletal sickness absence was more frequent in groups with greater time pressure at work, lower job control and more adverse beliefs about the work-relatedness of musculoskeletal disorders.
\end{abstract}

Conclusions Musculoskeletal sickness absence might be reduced by eliminating excessive time pressures in work, maximising employees' responsibility and control and providing flexibility of duties for those with disabling symptoms. Care should be taken not to overstate work as a cause of musculoskeletal injury.

\section{INTRODUCTION}

Absence from work because of sickness is disruptive and expensive. For example, the annual cost to the national economy of the UK has been estimated at around $£ 15$ billion. ${ }^{1}$ In most countries, the financial burden falls mainly on employers and/or the social security system, but sickness absence also impacts on the earnings of employees, and even where their income is protected, it can be damaging to their confidence and self-esteem.

While attributed ostensibly to ill health or injury, sickness absence is also influenced by the personality and attitudes of the worker, ${ }^{2-4}$ the physical and psychological demands of their job, ${ }^{5-}$ 13 social and cultural norms, ${ }^{3} 14 \quad 15$ and financial circumstances, such as availability and levels of sick pay and social security benefits. ${ }^{3}$ 15-19 Some of these factors vary by country and employer, and may be amenable to modification. Thus, if there were major differences in rates of sickness absence between workforces in different countries, and especially those carrying out similar types of work, identification of the causes might provide valuable pointers to practical preventive policies.

Attempts to compare levels of sickness absence between countries have been complicated by differences in the methods by which routine national statistics are compiled. ${ }^{20} 21 \mathrm{~A}$ few studies have circumvented this problem by using other, more uniform methods of data collection, ${ }^{11}{ }^{20-22}$ and some have suggested substantial variation in rates of absence. ${ }^{20-22}$ However, their design has not allowed detailed exploration of the reasons for the observed differences.

We present here, an analysis of data on sickness absence from the CUPID (Cultural and Psychosocial Influences on Disability) study, which used standardised methods to collect information on 47 occupational groups in 18 countries. ${ }^{23}$ The study focused on disability from musculoskeletal complaints, which in many countries are the major reason given for longer-term sickness absence. ${ }^{24-26}$ The aims of our analysis were to quantify the variation in rates of absence for musculoskeletal problems between occupational groups, and to explore factors that might underlie observed differences.

\section{METHODS}

The 47 occupational groups that we studied (table 1) fell into three broad categories-nurses (including nursing assistants), office workers and 'other workers' (mainly manual workers who carried out repetitive tasks with their hands or arms).

Data collection was carried out during 20062011, by teams of local investigators in each country, who identified populations suitable for study, and recruited participants from these populations. Each participant was asked to complete a questionnaire, either at interview or by selfadministration. The method of answering the questionnaire depended on considerations, such as the 
Table 1 Occupational groups included in the CUPID study

\begin{tabular}{|c|c|c|c|}
\hline Country & Occupational group & Response rate (\%) & Number of participants analysed \\
\hline \multirow[t]{3}{*}{ Brazil (BR) } & Nurses & 96 & 184 \\
\hline & Office workers & 97 & 278 \\
\hline & Other workers (sugarcane cutters) & 61 & 93 \\
\hline \multirow[t]{3}{*}{ Ecuador (EC) } & Nurses & 99 & 219 \\
\hline & Office workers & 100 & 243 \\
\hline & Other workers (flower plantation) & 99 & 227 \\
\hline Colombia (CO) & Office workers & 89 & 92 \\
\hline \multirow[t]{3}{*}{ Costa Rica (CR) } & Nurses & 91 & 220 \\
\hline & Office workers & 91 & 223 \\
\hline & Other workers (telephone call centre) & 94 & 205 \\
\hline \multirow[t]{3}{*}{ Nicaragua (NI) } & Nurses & 100 & 282 \\
\hline & Office workers & 100 & 285 \\
\hline & Other workers (machine operators) & 100 & 197 \\
\hline \multirow[t]{3}{*}{ UK (UK) } & Nurses & 42 & 256 \\
\hline & Office workers & 45 & 380 \\
\hline & Other workers (mail sorters) & 28 & 386 \\
\hline \multirow[t]{2}{*}{ Spain (SP) } & Nurses & 96 & 667 \\
\hline & Office workers & 98 & 438 \\
\hline \multirow[t]{2}{*}{ Italy (IT) } & Nurses & 76 & 536 \\
\hline & Other workers (assembly line) & 52 & 136 \\
\hline \multirow[t]{3}{*}{ Greece (GR) } & Nurses & 93 & 224 \\
\hline & Office workers & 99 & 199 \\
\hline & Other workers (postal clerks) & 91 & 140 \\
\hline \multirow[t]{2}{*}{ Estonia (EE) } & Nurses & 48 & 370 \\
\hline & Office workers & 53 & 202 \\
\hline \multirow[t]{3}{*}{ Lebanon (LB) } & Nurses & 96 & 184 \\
\hline & Office workers & 86 & 172 \\
\hline & Other workers (food production) & 98 & 137 \\
\hline \multirow[t]{2}{*}{ Iran (IR) } & Nurses & 94 & 246 \\
\hline & Office workers & 88 & 182 \\
\hline \multirow[t]{3}{*}{ Pakistan (PK) } & Nurses & 94 & 187 \\
\hline & Office workers & 100 & 180 \\
\hline & Other workers (mail sorters) & 96 & 222 \\
\hline \multirow[t]{4}{*}{ Sri Lanka (LK) } & Nurses & 95 & 236 \\
\hline & Office workers & 63 & 152 \\
\hline & Other workers-1 (mail sorters) & 100 & 250 \\
\hline & Other workers-2 (sewing machinists) & 86 & 151 \\
\hline \multirow[t]{4}{*}{ Japan (JP) } & Nurses & 76 & 592 \\
\hline & Office workers & 81 & 310 \\
\hline & Other workers-1 (transportation operatives) & 86 & 1017 \\
\hline & Other workers-2 (sales workers) & 98 & 355 \\
\hline \multirow[t]{2}{*}{ South Africa (SA) } & Nurses & 90 & 247 \\
\hline & Office workers & 83 & 229 \\
\hline Australia (AU) & Nurses & 39 & 250 \\
\hline \multirow[t]{3}{*}{ New Zealand (NZ) } & Nurses & 70 & 177 \\
\hline & Office workers & 52 & 145 \\
\hline & Other workers (mail sorters) & 50 & 113 \\
\hline
\end{tabular}

CUPID, Cultural and Psychosocial Influences on Disability.

literacy of participants, their geographical dispersion and the willingness of employers to allow employee time for interviews. Only one method was used for each occupational group, except in the UK, where most questionnaires were self-administered, but random samples of each occupational group were interviewed, and in South Africa, where most nurses were interviewed, but a few answered by self-administration.

The questionnaire was originally developed in English and then translated into local languages as necessary. The accuracy of translation was checked by independent back-translation, following which, amendments were made if required. Among other things, the questionnaire asked about demographic characteristics, age at which full-time education was completed, current occupation, pain during the past 12 months in each of six anatomical regions (low back, neck, shoulder, elbow, wrist/ hand and knee) as depicted in diagrams, fear-avoidance beliefs concerning low back and upper limb pain, distress from common somatic symptoms, mental health and total duration of 
sickness absence in the past 12 months $(0,1-5,6-30$ and $>30$ days) because of pain in each of the six specified anatomical regions, and because of other illness.

The questions about current occupation covered working hours, whether an average working day involved various specified physical activities, time pressures at work and job control, support, satisfaction and security. Exposure to physical loading at work was scored according to how many of five activities (lifting weights of $25 \mathrm{~kg}$ or more by hand, working for longer than $1 \mathrm{~h}$ in total with the hands above shoulder height, repeated bending and straightening of the elbow for longer than $1 \mathrm{~h}$ in total, use of a computer keyboard or other repeated movements of the wrist or fingers for longer than $4 \mathrm{~h}$ in total, and kneeling or squatting for longer than $1 \mathrm{~h}$ in total) were reported in an average working day. Time pressure at work was considered to be present if a participant reported either a target number of articles or tasks to be finished in the working day, or working under pressure to complete tasks by a fixed time; lack of support at work if help with difficulties was seldom or never provided by colleagues or a supervisor/manager; job dissatisfaction if overall, the participant felt dissatisfied or very dissatisfied with their employment; lack of control if there was seldom or never any choice in all of: a) how work was done, b) what was done at work, and c) work timetable and breaks; and job insecurity if the participant felt that the tenure of their employment would be 'rather unsafe' or 'very unsafe' if they were off work for 3 months with significant illness.

Questions regarding fear-avoidance beliefs were adapted from the Fear Avoidance Beliefs Questionnaire. ${ }^{27}$ Participants were deemed to have adverse beliefs about:

- The work-relatedness of musculoskeletal pain, if they completely agreed that either low back pain or arm pain (including pain in the shoulder or hands) is commonly caused by people's work.

- Physical activity, if either for someone with low back pain, or for someone with arm pain, they completely agreed both that physical activity should be avoided as it might cause harm, and that rest was needed to get better.

- Prognosis, if either for someone with low back pain or for someone with arm pain, they completely agreed that neglecting such problems can cause permanent health problems, and completely disagreed that such problems usually get better within 3 months.

Questions about distress from somatic symptoms were taken from the Brief Symptom Inventory, ${ }^{28}$ and somatising tendency was graded according to the number of symptoms from a total of five (faintness or dizziness, pains in the heart or chest, nausea or upset stomach, trouble getting breath, and hot or cold spells) that had been at least moderately distressing in the past week. Questions on mental health were taken from the Short Form-36 (SF-36) questionnaire, ${ }^{29}$ and scores were grouped to approximate thirds of the distribution in the combined study sample (denoted good, intermediate or poor mental health).

Data from the questionnaires were entered into a computer by local investigators, and after checks for errors, were transmitted to the coordinating centre in Southampton for collation and analysis.

In addition to the data on individual study participants, local investigators provided standardised information about the employment and socioeconomic circumstances of the occupational groups which they had recruited. This included the local unemployment rate at the time of the survey, entitlement to sick pay in the first 3 months of absence, availability of social security support for the unemployed, financial support for ill health retirement, whether a fee was payable for primary medical care and entitlement to compensation for work-related musculoskeletal disorders.

Further details of the methods of data collection and characteristics of occupational groups have been published elsewhere. $^{23}$

Analysis was carried out with Stata V.12.1 software, and as specified in the original protocol, was restricted to subjects aged 20-59 years who had worked in their job for at least 12 months. The main outcome analysed was prolonged sickness absence during the past 12 months because of musculoskeletal pain. This was defined to have occurred where, for at least one of the six anatomical regions listed in the questionnaire, the participant reported absence for $>5$ days in total during the past 12 months because of pain. We first assessed the extent to which this outcome varied by occupational group as compared with prolonged absence ( $>5$ days in total) for other illness.

Next, we explored associations of prolonged musculoskeletal sickness absence with personal characteristics that might contribute to differences in prevalence between occupational groups. For this, we used GLLAMM (generalised linear latent and mixed models) to fit two-level random-effects Poisson regression models with robust $\mathrm{SEs},{ }^{30}$ in which individuals were clustered by occupational group. Associations were summarised by prevalence rate ratios (PRRs) with associated 95\% CIs. From a final regression model including all the personal characteristics examined, we calculated the expected numbers of workers with prolonged musculoskeletal absence in each occupational group. Each individual's relative risk of prolonged absence was derived from the modelled risk estimates for the combination of risk factors to which he/she was exposed. The individual's probability of being a case was then calculated as the product of his/her relative risk, and a constant which was set such that the total expected number of cases across all participants in the study equalled the total number of cases observed. Finally, probabilities were summed across all individuals in an occupational group to give its expected number of cases.

The natural logarithms of these expected numbers were then used as an offset in Poisson regression analyses (with robust estimates of variance), taking the 47 occupational groups as the units of analysis, to explore the associations of prolonged musculoskeletal absence with risk factors acting at occupational group level. As well as the information on employment and socioeconomic circumstances that was provided by the local investigators, we analysed group-level risk factors that were defined by the prevalence of specified individual characteristics within each group. These prevalence rates were treated as continuous variables, and risks were estimated for 1 SD increase in each.

Next, we explored the extent to which personal and grouplevel risk factors might explain differences in the prevalence of prolonged musculoskeletal absence between occupational groups. For each group, we calculated the ratios of the observed prevalence of absence to that which would have been expected with no allowance for risk factors, with allowance for personal risk factors and with allowance for both personal and grouplevel risk factors. We then summarised the dispersions of these ratios across the 47 occupational groups by dot plots and geometric SDs (for this purpose the ratio in one occupational group with no observed cases was taken as 0.1 ).

Finally, to check for possible bias, we repeated analyses, excluding the five occupational groups in which the participation rate was $<50 \%$ (identified in table 1 ). 


\section{RESULTS}

Response rates among those invited to take part in the study were higher than $80 \%$ in 33 of the 47 occupational groups studied, and lower than $50 \%$ in only five groups (table 1). After elimination of subjects who did not meet the inclusion criteria that had been specified in the protocol (age 20-59 years, worked in current job for at least 12 months), and a further 317 for whom critical information was missing (eg, on sex or age), the CUPID study sample comprised a total of 12426 participants. Further details of exclusions and the characteristics of the study sample have been reported elsewhere. ${ }^{23}$ For the purposes of this report, we excluded an additional 10 participants with missing information on sickness absence for musculoskeletal pain. Thus, analysis was based on 12416 subjects (4348 men and 8068 women).

Figure 1 shows the 12-month prevalence of prolonged sickness absence for musculoskeletal pain and for other illness by occupational group. There was substantial variation, even between occupational groups within the same category. Thus, among office workers, the rate of prolonged absence for musculoskeletal pain ranged from $0 \%$ (95\% CI $0 \%$ to $2 \%$ ) in Pakistan to $13 \%(95 \%$ CI $9 \%$ to $18 \%)$ in South Africa, and in nurses, from $1 \%(95 \%$ CI $1 \%$ to $3 \%$ ) in Japan to $29 \%$ (95\% CI $23 \%$ to $36 \%$ ) in Costa Rica. Among the other workers, the lowest prevalence of prolonged absence for musculoskeletal pain was in sales/marketing personnel in Japan $(0.8 \%, 95 \%$ CI $0.2 \%$ to $2 \%)$, and the highest in production workers at a factory making pushchairs in Italy $(34 \%, 95 \%$ CI $26 \%$ to $42 \%)$. Rates of prolonged absence for musculoskeletal pain tended to correlate with those for other illness (Spearman correlation coefficient $=0.55$ ), but nurses reported relatively more absence because of musculoskeletal pain than office workers.

Table 2 summarises the relationship of prolonged sickness absence for musculoskeletal pain to personal characteristics. Findings are presented from three Poisson regression models. In Model 1, which included all the risk factors other than nonmusculoskeletal absence and number of painful anatomical sites, there were strong associations with exposure to physical loading, older age, somatising tendency and poor mental health.

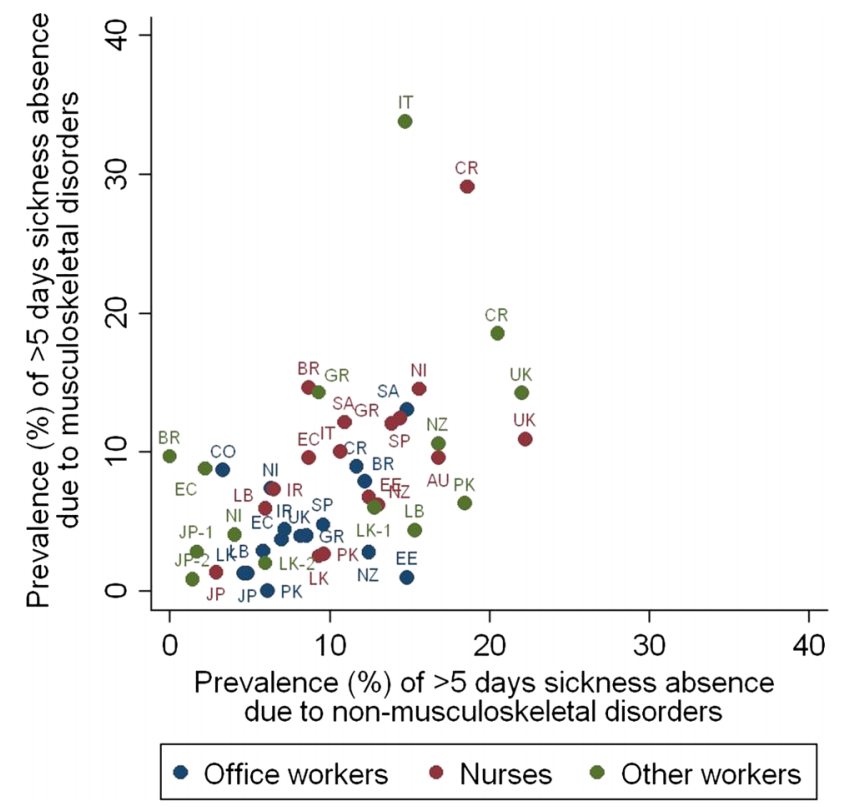

Figure 1 Twelve-month prevalence of prolonged sickness absence ( $>5$ days in total) for musculoskeletal pain and for other illness by occupational group.
Additionally, risk was elevated in workers, with adverse beliefs about the work-relatedness and prognosis of musculoskeletal pain, and tended to be higher in those with lower levels of education. Among the psychosocial aspects of work that were examined, the strongest associations were with time pressure at work and job dissatisfaction.

Addition of prolonged absence for non-musculoskeletal illness (Model 2) had minimal impact on the risk estimates for other variables, although such absence was itself an important risk factor (PRR 1.54, 95\% CI 1.22 to 1.95). When number of painful anatomical sites was also included (Model 3), many of the risk estimates were reduced. However, significant associations remained with older age, somatising tendency, poor mental health, time pressure at work, adverse beliefs about the prognosis of musculoskeletal disorders and prolonged absence in the past 12 months for non-musculoskeletal illness.

Table 3 shows associations with risk factors acting at the level of the occupational group, after allowance for all the personal characteristics that were examined in table 2 . When the grouplevel risk factors were analysed independently (Model 4), significant associations were found with lower group prevalence of adverse beliefs about musculoskeletal pain and physical activity, and higher group prevalence of reported time-pressure at work, lack of job control, and prolonged sickness absence for nonmusculoskeletal reasons. When effects were mutually adjusted in a single model that excluded only prevalence of nonmusculoskeletal absence (Model 5), additional associations emerged with higher group prevalence of adverse beliefs about the work-relatedness of musculoskeletal pain, and lower group prevalence of perceived job insecurity.

With adjustment also for group prevalence of prolonged absence for non-musculoskeletal reasons (Model 6), the associations with group prevalence of low job control and of job insecurity lost their significance. However, significant associations remained with group prevalence of adverse beliefs about the work-relatedness of musculoskeletal pain (PRR for 1 SD increase in prevalence $1.22,95 \%$ CI 1.01 to 1.47 ), adverse beliefs about musculoskeletal pain and physical activity (PRR $0.68,95 \%$ CI 0.53 to 0.85 ), time pressure at work (PRR 1.43, $95 \%$ CI 1.24 to 1.65 ) and absence in the past 12 months for non-musculoskeletal reasons (PRR 1.34, 95\% CI 1.16 to 1.56). Neither Model 5 nor Model 6 suggested any importantly higher risk when full sick pay was provided during the first 3 months of absence, or when compensation was available for workrelated musculoskeletal disorders.

Figure 2 shows the ratios of observed to expected 12-month prevalence of prolonged absence because of musculoskeletal disorders by occupational group, when expected numbers of cases were calculated with and without allowance for different risk factors. With increasing adjustment, the variation in ratios of observed to expected prevalence reduced but was still substantial (geometric SDs 2.5 with no adjustment, 2.1 with adjustment for personal risk factors, and 1.8 after adjustment also for grouplevel risk factors). The groups with the lowest ratios of observed to expected were office workers in Pakistan (ratio=0) and Estonia (0.17), while the highest ratios were in office workers from Colombia (3.6) and sugarcane cutters from Brazil (3.3).

When analyses were repeated with exclusion of the five occupational groups in which the participation rate was $<50 \%$, results were not materially altered.

\section{DISCUSSION}

Among the 47 occupational groups that we studied, there were more than 30 -fold differences in the prevalence of prolonged 
Table 2 Associations of personal characteristics with prolonged sickness absence ( $>5$ days in total) in past 12 months because of musculoskeletal pain

\begin{tabular}{|c|c|c|c|c|c|c|c|c|c|}
\hline \multirow[b]{2}{*}{ Risk factor } & \multirow[b]{2}{*}{ Number in sample } & \multicolumn{2}{|c|}{ Cases* } & \multicolumn{2}{|c|}{ Model 1† } & \multicolumn{2}{|c|}{ Model $2 \dagger$} & \multicolumn{2}{|c|}{ Model 3t } \\
\hline & & $\mathbf{N}$ & $(\%)$ & PRR & $(95 \% \mathrm{Cl})$ & PRR & $(95 \% \mathrm{Cl})$ & PRR & $(95 \% \mathrm{Cl})$ \\
\hline \multicolumn{10}{|l|}{ Sex } \\
\hline Male & 4348 & 235 & $(5.4)$ & 1 & & 1 & & 1 & \\
\hline Female & 8068 & 705 & $(8.7)$ & 1.17 & (1.00 to 1.37$)$ & 1.18 & (1.01 to 1.38$)$ & 1.02 & (0.88 to 1.19$)$ \\
\hline \multicolumn{10}{|l|}{ Age (years) } \\
\hline 20-29 & 3058 & 139 & $(4.5)$ & 1 & & 1 & & 1 & \\
\hline 30-39 & 3971 & 283 & (7.1) & 1.51 & (1.18 to 1.94$)$ & 1.50 & (1.16 to 1.93$)$ & 1.35 & (1.06 to 1.73$)$ \\
\hline $40-49$ & 3451 & 308 & $(8.9)$ & 1.74 & (1.35 to 2.23$)$ & 1.72 & (1.33 to 2.23 ) & 1.38 & (1.08 to 1.77$)$ \\
\hline $50-59$ & 1936 & 210 & $(10.8)$ & 2.13 & (1.72 to 2.63$)$ & 2.08 & (1.67 to 2.60$)$ & 1.60 & (1.29 to 1.98$)$ \\
\hline \multicolumn{10}{|l|}{ Age finished full-time education (years) } \\
\hline$\geq 20$ & 7244 & 486 & $(6.7)$ & 1 & & 1 & & 1 & \\
\hline $17-19$ & 3374 & 263 & $(7.8)$ & 1.18 & (0.98 to 1.42 ) & 1.17 & (0.97 to 1.41$)$ & 1.15 & (0.96 to 1.38$)$ \\
\hline $14-16$ & 1269 & 130 & $(10.2)$ & 1.29 & (0.99 to 1.68$)$ & 1.27 & (0.97 to 1.65$)$ & 1.28 & (1.00 to 1.65$)$ \\
\hline$<14$ & 470 & 57 & $(12.1)$ & 1.35 & (0.90 to 2.02 ) & 1.33 & (0.90 to 1.97$)$ & 1.21 & (0.82 to 1.78$)$ \\
\hline Unknown & 59 & 4 & $(6.8)$ & 0.79 & (0.28 to 2.19$)$ & 0.80 & (0.30 to 2.16$)$ & 0.97 & (0.36 to 2.56$)$ \\
\hline \multicolumn{10}{|l|}{ Number of distressing somatic symptoms in past week } \\
\hline 0 & 7399 & 392 & $(5.3)$ & 1 & & 1 & & 1 & \\
\hline 1 & 2609 & 212 & $(8.1)$ & 1.23 & (1.05 to 1.45$)$ & 1.22 & (1.04 to 1.43 ) & 1.09 & (0.93 to 1.27$)$ \\
\hline $2+$ & 2286 & 318 & $(13.9)$ & 1.69 & (1.46 to 1.97$)$ & 1.62 & (1.39 to 1.89$)$ & 1.24 & (1.08 to 1.44$)$ \\
\hline Missing & 122 & 18 & $(14.8)$ & 1.30 & (0.86 to 1.97 ) & 1.29 & (0.85 to 1.94$)$ & 1.17 & (0.76 to 1.81$)$ \\
\hline \multicolumn{10}{|l|}{ Mental health } \\
\hline Good & 4700 & 295 & $(6.3)$ & 1 & & 1 & & 1 & \\
\hline Intermediate & 3756 & 269 & $(7.2)$ & 1.14 & (0.98 to 1.32 ) & 1.13 & (0.98 to 1.31$)$ & 1.06 & (0.92 to 1.22$)$ \\
\hline Poor & 3885 & 366 & $(9.4)$ & 1.39 & (1.21 to 1.60$)$ & 1.36 & (1.19 to 1.57$)$ & 1.19 & (1.04 to 1.35$)$ \\
\hline Missing & 75 & 10 & $(13.3)$ & 1.75 & (0.83 to 3.68$)$ & 1.85 & (0.89 to 3.82$)$ & 1.63 & (0.76 to 3.52$)$ \\
\hline \multicolumn{10}{|l|}{ Number of physically loading activities } \\
\hline 0 & 874 & 35 & $(4.0)$ & 1 & & 1 & & 1 & \\
\hline 1 & 2198 & 94 & $(4.3)$ & 1.11 & (0.77 to 1.58 ) & 1.11 & (0.78 to 1.58$)$ & 0.99 & (0.70 to 1.40$)$ \\
\hline 2 & 3711 & 253 & $(6.8)$ & 1.37 & (0.94 to 1.99 ) & 1.37 & (0.94 to 1.98$)$ & 1.16 & (0.78 to 1.71$)$ \\
\hline 3 & 3068 & 286 & $(9.3)$ & 1.71 & (1.20 to 2.44$)$ & 1.72 & (1.21 to 2.44$)$ & 1.38 & (0.96 to 1.99$)$ \\
\hline 4 & 1750 & 165 & $(9.4)$ & 1.69 & (1.18 to 2.41$)$ & 1.68 & (1.18 to 2.40$)$ & 1.30 & (0.90 to 1.88$)$ \\
\hline 5 & 815 & 107 & $(13.1)$ & 2.09 & (1.44 to 3.03$)$ & 2.10 & (1.45 to 3.02$)$ & 1.49 & (1.02 to 2.18$)$ \\
\hline \multicolumn{10}{|l|}{ Psychosocial aspects of work } \\
\hline Work $>50$ hours per week & 2664 & 106 & $(4.0)$ & 0.84 & (0.65 to 1.09 ) & 0.84 & (0.65 to 1.09 ) & 0.90 & (0.69 to 1.17$)$ \\
\hline Time pressure at work & 9341 & 785 & (8.4) & 1.27 & (1.06 to 1.52$)$ & 1.27 & (1.06 to 1.52$)$ & 1.23 & (1.03 to 1.46$)$ \\
\hline Lack of support at work & 3013 & 296 & (9.8) & 1.08 & (0.93 to 1.25 ) & 1.09 & (0.94 to 1.25$)$ & 1.03 & (0.89 to 1.18$)$ \\
\hline Job dissatisfaction & 2535 & 223 & $(8.8)$ & 1.22 & (1.05 to 1.42 ) & 1.22 & (1.04 to 1.41$)$ & 1.10 & (0.95 to 1.27$)$ \\
\hline Lack of job control & 2663 & 250 & (9.4) & 1.06 & (0.95 to 1.18 ) & 1.05 & (0.94 to 1.17 ) & 1.04 & (0.94 to 1.16$)$ \\
\hline Job insecurity & 3912 & 277 & $(7.1)$ & 0.90 & (0.79 to 1.03$)$ & 0.91 & (0.79 to 1.04$)$ & 0.89 & (0.78 to 1.02$)$ \\
\hline \multicolumn{10}{|l|}{ Adverse beliefs about musculoskeletal pain } \\
\hline Work-relatedness & 4870 & 470 & $(9.7)$ & 1.24 & (1.10 to 1.39$)$ & 1.23 & (1.09 to 1.38$)$ & 1.10 & (0.98 to 1.24$)$ \\
\hline Physical activity & 2576 & 219 & $(8.5)$ & 1.14 & (0.97 to 1.33$)$ & 1.13 & (0.97 to 1.33 ) & 1.18 & (1.02 to 1.37$)$ \\
\hline Prognosis & 2079 & 240 & $(11.5)$ & 1.40 & (1.19 to 1.65$)$ & 1.38 & (1.17 to 1.62$)$ & 1.23 & (1.06 to 1.44$)$ \\
\hline$>5$ days absence in past 12 months for other illness & 1226 & 194 & $(15.8)$ & & & 1.54 & (1.22 to 1.95$)$ & 1.43 & (1.16 to 1.77$)$ \\
\hline \multicolumn{10}{|c|}{ Number of anatomical sites painful for $\geq 7$ days in past 12 months } \\
\hline $0-1$ & 7765 & 274 & $(3.5)$ & & & & & 1 & \\
\hline 2 & 1530 & 138 & $(9.0)$ & & & & & 2.16 & (1.78 to 2.62$)$ \\
\hline 3 & 1468 & 170 & $(11.6)$ & & & & & 2.67 & (2.21 to 3.22$)$ \\
\hline 4 & 975 & 159 & $(16.3)$ & & & & & 3.40 & (2.86 to 4.03$)$ \\
\hline 5 & 462 & 129 & $(27.9)$ & & & & & 4.55 & (3.78 to 5.48 ) \\
\hline 6 & 216 & 70 & (32.4) & & & & & 4.98 & (3.85 to 6.44 ) \\
\hline
\end{tabular}

${ }^{*}$ Number (\%) of cases among those exposed to risk factor.

tRisk estimates derived from a single Poisson regression model incorporating all variables for which results are presented.

PRR, prevalence rate ratio.

sickness absence attributed to musculoskeletal pain, and even for office workers carrying out similar occupational tasks, the variation was more than tenfold. Risk factors for such absence included older age, lower educational level, tendency to somatise, physical demands of work and prolonged sickness absence for non-musculoskeletal illness. Together, however, these 
Table 3 Associations of group-level risk factors with prolonged sickness absence ( $>5$ days in total) in past 12 months because of musculoskeletal disorders

\begin{tabular}{|c|c|c|c|c|c|c|c|c|c|}
\hline \multirow[b]{2}{*}{ Risk factor } & \multirow{2}{*}{$\begin{array}{l}\text { Number of occupational } \\
\text { groups exposed }\end{array}$} & \multicolumn{2}{|c|}{$\begin{array}{l}\text { Level of } \\
\text { exposure }\end{array}$} & \multicolumn{2}{|c|}{ Model $4^{*}$} & \multicolumn{2}{|c|}{ Model $5 t$} & \multicolumn{2}{|c|}{ Model $6 t$} \\
\hline & & Mean & (SD‡) & PRR & $(95 \% \mathrm{Cl})$ & PRR & $(95 \% \mathrm{Cl})$ & PRR & $(95 \% \mathrm{Cl})$ \\
\hline Unemployment rate $\geq 10 \%$ & 12 & & & 1.05 & (0.74 to 1.48$)$ & 0.98 & (0.61 to 1.57$)$ & 1.04 & (0.70 to 1.54$)$ \\
\hline Full sick pay in first three months absence & 25 & & & 1.11 & (0.80 to 1.54$)$ & 1.07 & (0.72 to 1.59$)$ & 1.06 & (0.74 to 1.52$)$ \\
\hline Social security for long-term unemployment & 28 & & & 1.28 & (0.94 to 1.75$)$ & 0.80 & (0.47 to 1.37$)$ & 0.87 & (0.48 to 1.58$)$ \\
\hline Financial support for ill-health retirement (sometimes or usually) & 28 & & & 1.31 & (0.90 to 1.89$)$ & 1.33 & (0.87 to 2.01$)$ & 0.98 & (0.65 to 1.46$)$ \\
\hline Payment for primary care (part or full) & 19 & & & 0.91 & (0.66 to 1.26$)$ & 1.02 & (0.65 to 1.61$)$ & 1.09 & (0.69 to 1.71$)$ \\
\hline Compensation for work-related musculoskeletal disorders (any) & 38 & & & 1.27 & (0.92 to 1.75$)$ & 1.11 & (0.73 to 1.70$)$ & 1.08 & (0.77 to 1.51$)$ \\
\hline Group prevalence (\%) of adverse beliefs about work-relatedness of musculoskeletal pain§ & 47 & 39 & 21 & 0.93 & (0.82 to 1.06$)$ & 1.24 & (1.04 to 1.48$)$ & 1.22 & (1.01 to 1.47$)$ \\
\hline Group prevalence (\%) of adverse beliefs about musculoskeletal pain and physical activity§ & 47 & 22 & 19 & 0.84 & (0.71 to 0.99$)$ & 0.62 & (0.48 to 0.81$)$ & 0.68 & (0.53 to 0.85$)$ \\
\hline Group prevalence (\%) of adverse beliefs about prognosis of musculoskeletal pain§ & 47 & 16 & 9 & 1.02 & (0.88 to 1.18$)$ & 1.02 & (0.85 to 1.22$)$ & 1.03 & (0.86 to 1.23$)$ \\
\hline Group prevalence (\%) of time pressure at work§ & 47 & 77 & 16 & 1.33 & (1.14 to 1.56$)$ & 1.54 & (1.30 to 1.82$)$ & 1.43 & (1.24 to 1.65$)$ \\
\hline Group prevalence (\%) of lack of support at work§ & 47 & 22 & 20 & 1.03 & (0.93 to 1.15$)$ & 1.04 & (0.92 to 1.17$)$ & 1.06 & (0.93 to 1.22$)$ \\
\hline Group prevalence (\%) of job dissatisfaction§ & 47 & 17 & 16 & 0.95 & $(0.76$ to 1.20$)$ & 1.10 & (0.91 to 1.33$)$ & 1.05 & (0.84 to 1.32$)$ \\
\hline Group prevalence $(\%)$ of lack of job control§ & 47 & 22 & 20 & 1.20 & (1.03 to 1.40$)$ & 1.28 & (1.12 to 1.47$)$ & 1.08 & (0.90 to 1.28$)$ \\
\hline Group prevalence (\%) of job insecurity§ & 47 & 31 & 18 & 0.91 & (0.74 to 1.11$)$ & 0.79 & (0.67 to 0.93$)$ & 0.94 & (0.78 to 1.13$)$ \\
\hline Group prevalence (\%) of $>5$ days absence in past 12 months for other illness $\S$ & 47 & 10 & 6 & 1.45 & (1.28 to 1.64$)$ & & & 1.34 & (1.16 to 1.56$)$ \\
\hline
\end{tabular}

Analysis was based on 47 occupational groups.

*Each risk factor analysed independently in a separate Poisson regression model.

tMutually adjusted risk estimates derived from a single Poisson regression model incorporating all the risk factors for which results are presented.

¥Mean and SD of prevalence (\%) across the 47 occupational groups.

$\S$ Analysed as a continuous variable. Risk estimates are for an increase of one SD.

PRR, prevalence rate ratio. 


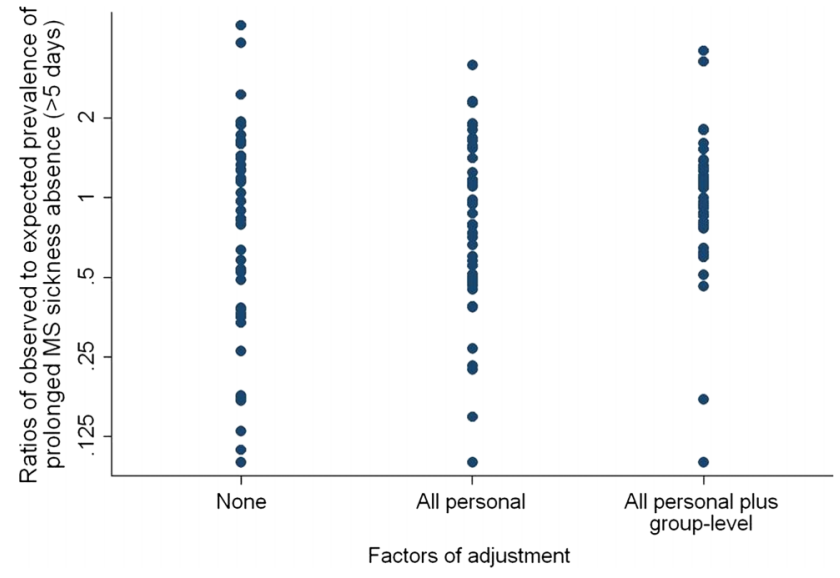

Figure 2 Ratios of observed to expected prevalence of prolonged sickness absence in past year ( $>5$ days in total) because of musculoskeletal pain in 47 occupational groups, according to level of adjustment for risk factors.

personal characteristics explained little of the disparity between occupational groups. After adjustment for personal characteristics, features of occupational groups that carried a higher risk of prolonged musculoskeletal absence included a higher prevalence of time pressure at work, and of prolonged sickness absence for non-musculoskeletal illness. However, the provision of sick pay and availability of compensation for work-related musculoskeletal disorders had no discernible impact.

Our investigation had the advantage of standardised data collection on large numbers of workers from multiple occupational groups in culturally diverse settings. Moreover, unlike most previous studies, it was able to assess simultaneously risk factors operating both at the level of the individual and of the occupational group.

It is possible that some workers with serious health problems were excluded from the study because they had left employment, or were unavailable when data were collected. This may have caused rates of prolonged sickness absence to be somewhat underestimated, but it is highly unlikely that it could account for differences between occupational groups of the magnitude that were observed.

We took as our outcome $>5$ days sickness absence because of pain in at least one of six anatomical sites, but did not separately analyse absence ascribed to pain at specific sites. This was because while the physical activities that may precipitate, aggravate, or be made difficult by musculoskeletal pain, differ by anatomical site, psychosocial risk factors for pain at different sites are remarkably similar. ${ }^{31-34}$ Furthermore, we were concerned that where participants were absent from work with pain at multiple sites (eg, neck and shoulder), they would have difficulty in reliably attributing the absence to pain at a single site.

We opted to focus on absence for more than 5 days in total, because this would be more burdensome for employers than absence of shorter duration, and was likely to be recalled more reliably. However, because of the way the questions were framed, we do not know how often the outcome included a continuous period of longer than 5 days away from work, and how frequently it was made up of several spells of absence, each of shorter duration. Analysis of absence for longer than 30 days in total during the past year, because of pain at an anatomical site produced broadly similar results (data not shown).

Like the outcome measures, exposures to potential risk factors were ascertained by self-report, and this raises the possibility that responses were biased by factors related to experience of musculoskeletal disorders. However, it seems unlikely that such bias could explain the major differences in prevalence of absence between occupational groups or the failure of personal risk factors to account for them.

When we began our analysis, we expected the inter-relation of risk factors to be complex. For example, exposure to stressful physical activities might increase the incidence of musculoskeletal disorders and thereby lead to absence, but it could also make it harder to perform a job when symptoms were present, irrespective of whether they were caused by work. And at group level, time pressures at work might have an effect on sickness absence for many types of illness, but a greater impact on musculoskeletal absence specifically. Therefore, to achieve a better understanding, we compared findings from statistical models with and without the inclusion of variables for the number of anatomical sites with pain and absence for non-musculoskeletal illness.

The associations that we found for prolonged musculoskeletal absence with older age and lower level of education were con-

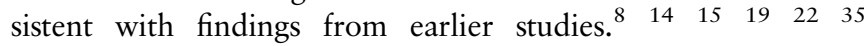
Similarly, the higher risk when more anatomical sites had been painful during the past year was unsurprising.

An association of sickness absence with the physical demands of work has also been reported before..$^{7-13} 36$ It is possible that experience of musculoskeletal pain increased participants' awareness and reporting of physical activities at work. However, the generally lower rates of musculoskeletal absence in office workers as compared with nurses (a physically more demanding job) suggest that the association was not due simply to biased reporting of activities by individuals with pain. That the association was still clearly present, albeit somewhat reduced, when adjustment was made for the number of anatomical sites with pain, indicates that the relationship did not occur simply because physical activities triggered musculoskeletal disorders. Additionally, a need to perform stressful physical activities makes it more difficult to work when pain is present.

Positive associations were observed with adverse beliefs about the work-relatedness and prognosis of musculoskeletal pain, and it is plausible that individuals who believe that musculoskeletal disorders are caused by work or carry a poor outlook, would be more likely to take absence when musculoskeletal symptoms occur. Similarly, adverse beliefs about harm from physical activity might deter some people from attending work, especially if their job was physically demanding.

Prolonged musculoskeletal absence was also associated with somatising tendency and poor mental health. Both these characteristics are known to be associated with, and to predict, musculoskeletal symptoms, ${ }^{31-34}$ and the substantial reductions in their risk estimates after adjustment for report of pain (Model 3, table 2) suggests that their relation to absence is explained largely by their associations with pain.

Even after allowance for other personal characteristics, prolonged musculoskeletal absence was strongly associated with individual history of prolonged absence for non-musculoskeletal reasons. This is likely to reflect, at least in part, a greater propensity of some individuals to take sickness absence, which goes beyond their demographic and occupational characteristics. Such individual differences in tendency to take sickness absence have been documented in earlier studies, and have been linked with various influences including upbringing and family situation. ${ }^{3} 1537$

When exploring determinants of musculoskeletal absence at the level of occupational groups, we considered not only the employment conditions and socioeconomic circumstances of workforces, but also a number of variables defined according to 
the prevalence of exposures reported by individual workers in each occupational group. These exposures had already been examined as risk factors at individual level, but it was possible that the perceptions of individual workers and their reporting of the exposures was influenced by whether or not they had suffered from musculoskeletal pain sufficient to cause prolonged sickness absence, and this could have led to bias. A group-level measure, which took account of reports from workers both with and without pain would be less prone to such bias. Furthermore, it was possible that these risk factors contributed to differences between occupational groups in a way that exceeded their influence on which workers within an occupational group took sickness absence. For example, inclination to take sickness absence might be influenced by a culture of absence within an occupational population, as well as being related to an individual's personal history of absence for nonmusculoskeletal illness.

Among the group-level risk factors, two showed associations in Model 5 which disappeared when prevalence of prolonged nonmusculoskeletal absence was added to form Model 6, suggesting that they had an effect on sickness absence in general, and not specifically from musculoskeletal disorders. These were a higher prevalence of low job control and a lower prevalence of job insecurity. Both these findings are highly plausible. Low job control may reduce workers' scope to modify their activities in response to health problems, as well as making their job less rewarding, and has been linked with sickness absence in previous studies. 569131935 38-40 On the other hand, job insecurity would be expected to act as a disincentive to sickness absence, and has been associated with lower rates of absence in a previous study. ${ }^{41}$

Other factors showed associations with musculoskeletal absence even in the model that included absence for non-musculoskeletal illness. As well as prolonged absence for non-musculoskeletal illness, these were the group prevalence of time pressure at work (higher risk); adverse beliefs about the work-relatedness of musculoskeletal pain (higher risk) and adverse beliefs about musculoskeletal pain and physical activity (lower risk). The relation to absence for non-musculoskeletal illness is likely to be explained, at least in part, by differences in absence culture. ${ }^{3} 1542$ Similarly, if there is a widespread belief among a workforce that occupational activities are an important cause of musculoskeletal disorders, that could create a culture in which workers are more aware of musculoskeletal symptoms, and more likely to withdraw from work when they occur. Time pressures may render work especially difficult when musculoskeletal symptoms occur, and thereby increase absence. More difficult to explain is the inverse association with group prevalence of adverse beliefs about physical activity. This was apparent when the group level risk factors were analysed individually (Model 4), as well as when their effects were mutually adjusted (Models 5 and 6), but was contrary to the findings from analysis of individual risk factors, in which such beliefs carried a higher risk. Despite its high statistical significance, the association may have occurred simply by chance.

By contrast with findings from several earlier studies, ${ }^{3} 16171922$ we found no indication that provision of sick pay was associated with a higher frequency of absence for musculoskeletal pain. This may be because our definition of prolonged absence which could have included some individuals with repeated short episodes of absence, as well as those who were absent for longer continuous periods, differed from the outcome measures used in other investigations.

Our findings indicate that we have failed to capture all the factors responsible for large differences between occupational groups in the prevalence of prolonged sickness absence for musculoskeletal pain (figure 2). Nevertheless, they suggest several approaches by which employers might reduce sickness absence from common musculoskeletal disorders. Care should be taken not to overstate work as a cause of musculoskeletal injury, since adverse beliefs about work-relatedness appear to be associated with a higher risk of absence. Where possible, work should be organised to reduce excessive time pressures, and to allow greater flexibility of activities for workers who have symptoms which make their normal job unusually difficult. Also, where there is a culture of absence, this might be reduced by maximising the responsibility that is given to employees, and the control which they have over their work. The impact of such measures could usefully be investigated by intervention studies.

\section{What this paper adds}

- Earlier studies have suggested substantial international variation in rates of sickness absence, but their design has not allowed detailed exploration of the reasons for the observed differences.

- In our large international survey, personal risk factors for prolonged musculoskeletal absence included older age, lower educational level, tendency to somatise, physical loading at work and prolonged absence for non-musculoskeletal illness, but these explained little of the $>30$-fold variation in prevalence between occupational groups.

- After adjustment for individual characteristics, prolonged musculoskeletal absence was more frequent in groups with greater time pressure at work, lower job control and more adverse beliefs about the work-relatedness of musculoskeletal disorders.

- Our findings suggest that musculoskeletal sickness absence might be reduced by eliminating excessive time pressures in work, maximising employees' responsibility and control, and providing flexibility of duties for those with disabling symptoms, and the impact of such measures could usefully be investigated by intervention studies.

Acknowledgements We thank: Pietro Muñoz, Patricio Oyos, Gonzalo Albuja, María Belduma and Francisco Lara for their assistance with data collection in Ecuador; Patrica Monge, Melania Chaverri and Freddy Brenes, who helped with data collection in Costa Rica; Aurora Aragón, Alberto Berríos, Samaria Balladares and Martha Martínez who helped with data collection in Nicaragua; Alfredo José Jirón who assisted with data entry in Nicaragua; Catalina Torres for translation and piloting of the questionnaire in Spain; Ben and Marie Carmen Coggon for back-translation of the Spanish questionnaire; Cynthia Alcantara, Xavier Orpella, Josep Anton Gonzalez, Joan Bas, Pilar Peña, Elena Brunat, Vicente San José, Anna Sala March, Anna Marquez, Josefina Lorente, Cristina Oliva, Montse Vergara and Eduard Gaynés for their assistance with data collection in Spain; Natale Battevi, Lorenzo Bordini, Marco Conti and Luciano Riboldi who carried out data collection in Italy; Paul Maurice Conway for back translation of the Italian questionnaire; Tiina Freimann, who helped with data collection in Estonia; the Deputy for Training and Research, Shahroud University of Medical Sciences, for financial support of data collection in Iran; Asad Ali Khan for supervision of data collection and checking in Pakistan; Khalil Qureshi for training of field workers and supervision of data collection and checking in Pakistan; and Masami Hirai, Tatsuya Isomura, Norimasa Kikuchi, Akiko Ishizuka and Takayuki Sawada for their help with data collection and management in Japan; Monash University which funded data collection in Australia through its grant schemes; NHMRC which supported Helen Kelsall and Donna Urquhart in Australia through fellowships; the Ministry of Higher Education in Malaysia which supported Victor Hoe in Australia; and the Health Research Council of New Zealand which funded data collection in New Zealand. Data collection in Central America and Colombia was supported by the Southwest Center for Occupational and Environmental Health at the University of Texas Health Science 
Center research training grant from the NIH Fogarty International Center. We are particularly grateful to the Colt Foundation, which funded data collection in Brazil, Ecuador, Costa Rica, Nicaragua, UK, Greece, Estonia, Lebanon, Pakistan and South Africa; all the organisations that allowed us to approach their employees; and all the workers who kindly participated in the study.

Collaborators Vanda E Felli, School of Nursing, University of São Paulo, São Paulo, Brazil. Raul Harari, Corporación para el Desarrollo de la Producción y el Medio Ambiente Laboral - IFA (Institute for the Development of Production and the Work Environment), Quito, Ecuador. Lope H Barrero, School of Engineering, Pontificia Universidad Javeriana, Bogotá, Colombia. Sarah A. Felknor, Southwest Center for Occupational and Environmental Health, The University of Texas Health Science Center at Houston School of Public Health, Houston, Texas, USA; Center for Disease Control and Prevention/National Institute for Occupational Safety and Health, Atlanta, USA. David Gimeno, Southwest Center for Occupational and Environmental Health, The University of Texas Health Science Center at Houston School of Public Health, Houston, Texas, USA. Anna Cattrell, Medical Research Council Social, Genetic and Developmental Psychiatry Centre, Institute of Psychiatry, Kings College, London, UK. Matteo Bonzini, Epidemiology and Preventive Medicine Research Center, University of Insubria, Varese, Italy. Eleni Solidaki, Department of Social Medicine, Medical School, University of Crete, Heraklion, Greece. Eda Merisalu, Department of Public health, University of Tartu, Estonia. Rima R. Habib, Department of Environmental Health, Faculty of Health Sciences, American University of Beirut, Beirut, Lebanon. Farideh Sadeghian, Department of Occupational Health, Faculty of Health, Shahroud University of Medical Sciences, Shahroud, Iran. M Masood Kadir, Department of Community Health Sciences, Aga Khan University, Karachi, Pakistan. Sudath SP Warnakulasuriya, Department of Medical Education and Health Sciences, Faculty of Medical Sciences, University of Sri Jayewardenepura, Gangodawila, Nugegoda, Sri Lanka. Ko Matsudaira, Clinical Research Centre for Occupational Musculoskeletal Disorders, Kanto Rosai Hospital, Kawasaki, Japan. Busisiwe Nyantumbu, National Institute for Occupational Health, National Health Laboratory Service, Johannesburg, South Africa; Faculty of Health Sciences, University of Witwatersrand, Johannesburg, South Africa. Malcolm R Sim, Department of Epidemiology and Preventive Medicine, School of Public Health and Preventive Medicine, Monash University, Melbourne, Victoria, Australia. Helen Harcombe, Department of Preventive and Social Medicine, University of Otago, Dunedin, New Zealand. Ken Cox, Medical Research Council Lifecourse Epidemiology Unit, University of Southampton, Southampton, UK. Maria H Marziale, School of Nursing of Ribeirão Preto, University of São Paulo, São Paulo, Brazil. Leila M Sarquis, Federal University of Paraná, Curitiba-PR, Brazil. Florencia Harari, Corporación para el Desarrollo de la Producción y el Medio Ambiente Laboral - IFA (Institute for the Development of Production and the Work Environment), Quito, Ecuador. Rocio Freire, Corporación para el Desarrollo de la Producción y el Medio Ambiente Laboral - IFA (Institute for the Development of Production and the Work Environment), Quito, Ecuador. Natalia Harari, Corporación para el Desarrollo de la Producción y el Medio Ambiente Laboral - IFA (Institute for the Development of Production and the Work Environment), Quito, Ecuador. Magda V Monroy, School of Engineering, Pontificia Universidad Javeriana, Bogotá, Colombia. Leonardo A Quintana, School of Engineering, Pontificia Universidad Javeriana, Bogotá, Colombia. Marianela Rojas, Institute for Studies on Toxic Substances (IRET), National University of Costa Rica, Heredia, Costa Rica. Eduardo J. Salazar Vega, Southwest Center for Occupational and Environmental Health, The University of Texas Health Science Center at Houston School of Public Health, Houston, Texas, USA. E Clare Harris, Medical Research Council Lifecourse Epidemiology Unit, University of Southampton, Southampton, UK. George Delclos, Center for Research in Occupational Health (CiSAL), Universitat Pompeu Fabra, Barcelona, Spain; CIBER of Epidemiology and Public Health, Spain; Southwest Center for Occupational and Environmental Health, The University of Texas Health Science Center at Houston School of Public Health, Houston, Texas, USA. Michele Carugno, Department of Clinical Sciences and Community Health, Università degli Studi di Milano, Milan, Italy. Marco M Ferrario, Epidemiology and Preventive Medicine Research Center, University of Insubria, Varese, Italy. Angela C Pesatori, Department of Clinical Sciences and Community Health, Università degli Studi di Milano, Milan, Italy; Fondazione Ca' Granda Ospedale Maggiore Policlinico, Milan, Italy. Leda Chatzi, Department of Social Medicine, Medical School, University of Crete, Heraklion, Greece. Panos Bitsios, Department of Psychiatry, Medical School, University of Crete, Heraklion, Greece. Manolis Kogevinas, CIBER of Epidemiology and Public Health, Spain; Centre for Research in Environmental Epidemiology (CREAL), Barcelona, Spain; IMIM (Hospital del Mar Research Institute), Barcelona, Spain; National School of Public Health, Athens, Greece. Kristel Oha, North Estonia Medical Centre, Tallinn, Estonia. Tuuli Sirk, Põlva Hospital, Põlva, Estonia. Ali Sadeghian, Klinikum Leverkusen, Leverkusen, Germany. Roshini J Peiris-John, Department of Physiology, Faculty of Medical Sciences, University of Sri Jayewardenepura, Gangodawila, Nugegoda, Sri Lanka; Section of Epidemiology and Biostatistics, School of Population Health, Faculty of Medical and Health Sciences, University of Auckland, Auckland, New Zealand. Nalini Sathiakumar, Department of Epidemiology, School of Public Health, University of Alabama at Birmingham, Birmingham, Alabama, USA. A Rajitha Wickremasinghe, Faculty of Medicine, University of Kelaniya, Kelaniya, Sri Lanka. Noriko Yoshimura, Department of Joint
Disease Research, University of Tokyo, Tokyo, Japan. Helen L Kelsall, Department of Epidemiology and Preventive Medicine, School of Public Health and Preventive Medicine, Monash University, Melbourne, Victoria, Australia. Victor C W Hoe, Department of Epidemiology and Preventive Medicine, School of Public Health and Preventive Medicine, Monash University, Melbourne, Victoria, Australia; Centre for Occupational and Environmental Health, Department of Social and Preventive Medicine, Faculty of Medicine, University of Malaya, Kuala Lumpur, Malaysia. Donna M Urquhart, Department of Epidemiology and Preventive Medicine, School of Public Health and Preventive Medicine, Monash University, Melbourne, Victoria, Australia. Sarah Derrett, Injury Prevention Research Unit, Department of Preventive and Social Medicine, University of Otago, Dunedin, New Zealand. David McBride, Department of Preventive and Social Medicine, University of Otago, Dunedin, New Zealand. Peter Herbison, Department of Preventive and Social Medicine, University of Otago, Dunedin, New Zealand. Andrew Gray, Department of Preventive and Social Medicine, University of Otago, Dunedin, New Zealand

Contributors Brazil: Vanda E Felli-Principal Investigator in Brazil and coordinator of data collection for nurses; Maria $\mathrm{H}$ Marziale-Coordinator of data collection in sugarcane cutters; Leila M Sarquis-Coordinator of data collection for office workers. Ecuador: Raúl Harari-Principal Investigator in Ecuador; Florencia HarariCoordinator of data collection for office workers; Rocío Freire-Coordinator of data collection for nurses; Natalia Harari-Coordinator of data collection for flower plantation workers. Colombia: Lope H Barrero-Principal Investigator in Colombia; Magda V Monroy - Data collection in Colombia; Leonardo A Quintana-Oversight of study design and conduct in Colombia. Costa Rica: Marianela RojasCoordinaotor of data collection and supervised data entry and checking in Costa Rica. USA: Sarah A. Felknor-Joint Principal Investigator for Costa Rica and Nicaragua with input also to study design in Colombia; David Gimeno-Joint Principal Investigator for Costa Rica and Nicaragua; Eduardo J. Salazar VegaCollation and checking of data from Costa Rica and Nicaragua. UK: DC-Principal Investigator for the international CUPID study. Initiated and designed the study, oversaw statistical analysis, and wrote first draft of manuscript; GN-Carried out statistical analysis; KTP-Contributed to design of international study; Ken CoxCollation and checking of international dataset; E Clare Harris-Supervision of data collection in UK; Anna Cattrell-Data collection in UK. Spain: SV-P-Collection, preparation and checking of data in Spain; CS—Joint Principal Investigator in Spain; JMM-Supervision of data collection and preparation in Spain; George DelclosSupervision of data collection in Spain; FGB-Joint Principal Investigator in Spain. Italy: Matteo Bonzini-Principal Investigator for Italy; Michele Carugno-Collection and checking of data in Italy; Marco M Ferrario-Contributed to design of data collection in Italy; Angela C Pesatori-Contributed to design of data collection in Italy. Greece: Eleni Solidaki-Collection, preparation and checking of data in Greece; Leda Chatzi-Contributed to data collection and preparation in Greece; Panos Bitsios-Contributed to data collection and preparation in Greece; Manolis Kogevinas-Principal Investigator for data collection in Greece. Estonia: Eda Merisalu-Principal Investigator in Estonia; Kristel Oha-Carried out data collection in Estonia; Tiina Freimann-Data preparation in Estonia. Lebanon: Rima R HabibPrincipal Investigator in Lebanon. Iran: Farideh Sadeghian—Principal Investigator in Iran; Ali Sadeghian—Oversight of data collection in Iran. Pakistan: M Masood Kadir —Principal Investigator in Pakistan. Sri Lanka: Sudath SP WarnakulasuriyaCollection, preparation and checking of data in Sri Lanka; Roshini J Peiris-JohnSupervision of data collection in Sri Lanka; Nalini Sathiakumar-Supervision of data collection in Sri Lanka; A Rajitha Wickremasinghe-Principal Investigator for Sri Lanka. Japan: Ko Matsudaira—Principal Investigator for Japan; Noriko Yoshimura - Contributed to design of data collection in Japan, including translation of questionnaire. South Africa: Busisiwe Nyantumbu-Collection, preparation and checking of data in South Africa. Australia: Malcolm R Sim—Principal investigator for Australia; Helen L Kelsall-Coordinated collection, preparation and checking of data in Australia; Victor CW Hoe-Contributed to collection, preparation and checking of data in Australia; Donna M Urquhart-Contributed to questionnaire development and data collection in Australia. New Zealand: Helen HarcombeContributed to data collection and obtaining funding in New Zealand; Sarah Derrett - Contributed to collection, analysis and interpretation of data and obtaining funding in New Zealand; David McBride-Contributed to initiation of study in New Zealand, and obtaining funding; Peter Herbison-Contributed to analysis and interpretation of data; Andrew Gray-Contributed to acquisition of data and supervision of study in New Zealand. In addition, all authors provided critical input to the draft manuscript and its subsequent revision..

Funding Funding for the central coordination of the CUPID study was provided by the UK Medical Research Council. In addition, support for data collection in individual countries was obtained from the following sources: Brazil: Colt Foundation (CF/03/05). Ecuador: Colt Foundation (CF/03/05). Colombia: NIH Grant 5D43 TW00 0644-13, sub-award 0005919H; NIH Grant 5D43 TW00 0644-15, sub-award 0005919); and Pontificia Universidad Javeriana. Costa Rica: Colt Foundation (CF/O3/ 05). Nicaragua: Colt Foundation (CF/03/05). UK: Colt Foundation (CF/03/05). Spain: Spanish Health Research Fund (FIS 070422), and Epidemiology and Public Health CIBER. Carlos III Institute of Health. Ministry of Science and Innovation. Italy: Department of Experimental Medicine, University of Insubria, Varese, Italy. Greece: 
Colt Foundation (CF/03/05). Estonia: Colt Foundation (CF/03/05). Lebanon: Colt Foundation (CF/03/05). Iran: Deputy for Training and Research, Shahroud University of Medical Sciences. Pakistan: Colt Foundation (CF/03/05). Sri Lanka: International Training and Research in Environmental and Occupational Health (ITREOH) Program of the University of Alabama at Birmingham (Grant number 5 D43 TW05750 from the National Institutes of Health and the Fogarty International Center (NIH-FIC)). Japan: University of Tokyo. South Africa: Colt Foundation (CF/03/05). Australia: Monash University Strategic Grant Scheme and Monash University Near Miss Grant for NHMRC projects in 2008. HKL and DMU were supported by fellowships from NHMRC, and VCWH by the Ministry of Higher Education in Malaysia. New Zealand: Health Research Council of New Zealand (International Investment Opportunity Fund Grant).

\section{Competing interests None.}

Ethics approval Brazil: National Committee for Ethics in Research and Ethics Committee of University Hospital of University of Sao Paolo. Ecuador: Ethical Committee of Biomedicine, Central University of Ecuador. Colombia: Ethics Committee of the School of Medicine, Pontificia Universidad Javeriana, Bogotá, Colombia. Costa Rica: Ethics Committee of the Universidad Nacional in Costa Rica. Nicaragua: Ethics Committee for Biomedical Research of the Universidad Nacional Autonoma de Nicaragua. UK: National Research Ethics Service Committee South Central—Berkshire. Spain Parc Salut Mar Ethics Committee of Barcelona. Italy: Institutional Review Boards, Fondazione IRCCS Ca' Granda—Ospedale Maggiore Policlinico (Milan) and Ospedale di Circolo Fondazione Macchi (Varese). Greece: Scientific Board Committee of the University Hospital of Heraklion. Estonia: Ethics Review Committee on Human Research, University of Tartu. Lebanon: Institutional Review Board, American University of Beirut. Iran: Research Committee of Shahroud University of Medical Sciences. Pakistan: Ethical Review Committee of Aga Khan University. Sri Lanka: Ethical review Committee, Faculty of Medical Sciences, University of Sri Jayawardenepura. Japan: University of Tokyo Ethics Committee. South Africa: University of Witwatersrand Ethics Committee for Human Subjects. Australia: Monash University Human Research Ethics Committee and the Alfred Ethics Committee. New Zealand: New Zealand Multi-region Ethics Committee.

Provenance and peer review Not commissioned; externally peer reviewed.

Open Access This is an Open Access article distributed in accordance with the Creative Commons Attribution Non Commercial (CC BY-NC 3.0) license, which permits others to distribute, remix, adapt, build upon this work non-commercially, and license their derivative works on different terms, provided the original work is properly cited and the use is non-commercial. See: http://creativecommons.org/ licenses/by-nc/3.0/

\section{REFERENCES}

1 Black C, Frost D. Health at work - an independent review of sickness absence. London: The Stationery Office, 2011. (http://webarchive.nationalarchives.gov.uk/+/http://www. dwp.gov.uk/docs/health-at-work.pdf (accessed May 5 2013))

2 Steers RM, Rhodes SR. Major influences on employee attendance: a process model. J Appl Psychol 1978;63:391-407.

3 Alexanderson K. Sickness absence: a review of performed studies with focused on levels of exposures and theories utilized. Scand J Soc Med 1998:26:241-9.

4 Beemsterboer W, Stewart R, Groothoff J, et al. A literature review on sick leave determinants (1984-2004). Int J Occup Med Environ Health 2009:22:169-79.

5 Michie S, Williams S. Reducing work related psychological ill health and sickness absence: a systematic literature review. Occup Environ Med 2003:60:3-9.

6 Gimeno D, Benavides FG, Amick BC, et al. Psychological factors and work related sickness absence among permanent and non-permanent employees. J Epidemiol Comm Health 2004;58:870-6.

7 Hansson T, Jensen I. Sickness absence due to back and neck disorders. Scand J Public Health 2004;32(Suppl 63):109-51.

8 IJzelenberg W, Burdorf A. Risk factors for musculoskeletal symptoms and ensuing health care use and sick leave. Spine 2005:30:1550-6.

9 Gheldof ELM, Vinck J, Vlaeyen JWS, et al. The differential role of pain, work characteristics, and pain-related fear in explaining back pain and sick leave in occupational settings. Pain 2005;113:71-81.

10 Melchior M, Krieger N, Kawachi I, et al. Work factors and occupational class disparities in sickness absence: findings from the GAZEL cohort study. Am J Public Health 2005:95:1206-12.

11 Lund T, Christensen KB, Vaez M, et al. Differences in sickness absence in Sweden and Denmark: the cross national HAKNAK study. Eur J Public Health 2008;19:343-9.

12 Lund T, Labriola M. Sickness absence in Denmark-research, results, and reflections. Scand J Work Environ Health Supp/ 2009;7:5-14

13 Foss $L$, Gravseth HM, Kristensen $\mathrm{P}$, et al. The impact of workplace risk factors on long-term musculoskeletal sickness absence. J Occup Environ Med 2011:53:1478-82.
14 Joensuu M, Lindström K. Sickness absence and stress factors at work. Stress Impact. http://www.fahs.surrey.ac.uk/stress_impact/publications/wp1/WP1-Ch3_Stress\% 20Impact\%20Literature[1].pdf.

15 Markussen S, Røed K, Røgeberg OJ, et al. The anatomy of absenteeism. J Health Economics 2011:30:277-92.

16 Drago $\mathrm{R}$, Wooden M. The determinants of labor absence: economic factors and workgroup norms across countries. Ind Labor Relations Rev 1992;45:764-78.

17 Osterkamp R, Röhn O. Being on sick leave: possible explanations for differences of sick-leave days across countries. CESifo Economic Studies 2007;53:97-114

18 Benavides FG, Serra C, Dominguez R, et al. Does return to work occur earlier after work-related sick leave episodes than after non-work-related sick leave episodes? A retrospective cohort study in Spain. Occup Environ Med 2009:66:63-7.

19 Allebeck P, Mastekaasa A. Risk factors for sick leave-general studies. Scand J Public Health 2004:32(Suppl 63):49-108.

20 Prins $R$, de Graaf A. Comparison of sickness absence in Belgian, German, and Dutch firms. Br J Indust Med 1986:43:529-36.

21 Gimeno D, Benavides FG, Benach J, et al. Distribution of sickness absence in European Union countries. Occup Environ Med 2004;61:867-9.

22 Barmby TA, Ercolani MG, Treble JG. Sickness absence: an international comparison. Economic J 2002;112:F315-31

23 Coggon D, Ntani G, Palmer KT, et al. The CUPID (Cultural and Psychosocial Influences on Disability) study: methods of data collection and characteristics of study sample. PLoS One 2012;7:e39820.

24 Ihlebaek C, Brage S, Eriksen HR. Health complaints and sickness absence in Norway 1996-2003. Occup Med 2007:57:43-9.

25 Schneider E, Irastorza X. OSH in figures: work-related musculoskeletal disorders in the EU—facts and figures. European Agency for Safety and Health at Work, 2010. http://osha.europa.eu/en/publications/reports/TERO09009ENC.

26 Office for National Statistics. Sickness absence in the labour market, 2012. http:// www.ons.gov.uk/ons/dcp171776_265016.pdf.

27 Waddell G, Newton M, Henderson I, et al. A Fear-Avoidance Beliefs Questionnaire (FABQ) and the role of fear-avoidance beliefs in chronic low back pain and disability. Pain 1993;52:157-68.

28 Derogatis LR, Melisoratos N. The brief symptom inventory: an introductory report. Psychol Med 1983;13:595-605

29 Ware JE, Sherbourne CD. The MOS 36-item short-form health survey (SF-36). Med Care 1992;30:473-83.

30 Rabe-Hesketh S, Skrondal A. Mulitlevel and longitudinal modelling using stata. College Station, Texas: Stata press, 2008

31 Macfarlane GJ, Hunt IM, Silman AJ. Role of mechanical and psychosocial factors in the onset of forearm pain: prospective population based study. $\mathrm{Br}$ Med J 2000;321:676-9.

32 Palmer KT, Reading I, Calnan M, et al. Does knee pain in the community behave like a regional pain syndrome? Prospective cohort study of incidence and persistence. Ann Rheum Dis 2007:66:1190-4.

33 Palmer KT, Reading I, Linaker C, et al. Population-based cohort study of incident and persistent arm pain: role of mental health, self-rated health and health beliefs. Pain 2008:136:30-7.

34 Vargas-Prada S, Serra C, Martinez J, et al. Psychological and culturally-influenced risk factors for the incidence and persistence of low back pain and associated disability in Spanish workers: findings from the CUPID study. Occup Environ Med 2013;70:57-62.

35 Henderson M, Clark C, Stansfeld S, et al. A lifecourse approach to long-term sickness absence-a cohort study. PLoS One 2012;7:e36645.

36 Hoogendoorn WE, Bongers PM, de Vet HCW, et al. High physical work load and low job satisfaction increase the risk of sickness absence due to low back pain: results of a prospective cohort study. Occup Environ Med 2002;59:323-8.

37 Kristensen P, Bjerkedal T, Irgens LM. Early life determinants of musculoskeletal sickness absence in a cohort of Norwegians born in 1967-1976. Soc Sci Med 2007:64:646-55.

38 Niedhammer I, Bugel I, Goldberg $\mathrm{M}$, et al. Psychosocial factors at work and sickness absence in the Gazel cohort: a prospective study. Occup Environ Med 1998:55:735-41.

39 Ala-Mursula L, Vahtera J, Kivimäki M, et al. Employee control over working times: associations with subjective health and sickness absences. J Epidemiol Comm Health 2002;56:272-8.

40 Duijts SFA, Kant I, Swaen GMH, et al. A meta-analysis of observational studies identifies predictors of sickness absence. J Clin Epidemiol 2007;60:1105-15.

41 Benavides FG, Benach J, Diez-Roux AV, et al. How do types of employment relate to health indicators? Findings from the second European survey on working conditions. J Epidemiol Comm Health 2000;54:494-501.

42 Virtanen $\mathrm{P}$, Siukola A, Luukkaala T, et al. Sick leaves in four factories-do characteristics of employees and work conditions explain differences in sickness absence between workplaces? Scand J Work Environ Health 2008:34:260-6. 